\title{
Cytotoxic effect of transdermal invasomal anastrozole gel on MCF-7 breast cancer cell line
}

\author{
K. Vidya, P. K. Lakshmi* \\ Department of Pharmaceutics, G. Pulla Reddy College of Pharmacy, Mehdipatnam, Hyderabad, India.
}

\section{ARTICLE INFO \\ Received on: 21/12/2018 \\ Accepted on: 23/02/2019 \\ Available online: 30/03/2019}

\section{Key words:}

Anastrozole, breast cancer, invasomes, full factorial design, cell line study.

\begin{abstract}
Introduction: Anastrozole is an anti-cancer drug, an effective aromatase inhibitor for the treatment of breast cancer in post-menopausal women. As it undergoes extensive first-pass metabolism and has many side effects related to oral use, it has been envisaged to develop anastrozole invasomes in the form of transdermal gel.

Objective: The objective of this work was to prepare, characterize, and evaluate invasomal gel of anastrozole.

Materials and Methods: Invasomes were prepared by thin layer film hydration method using Phospholipon $80 \mathrm{H}$, fenchone (terpene), and ethanol. The optimized invasomes were incorporated into sodium carboxy methyl cellulose gel. Prepared formulations were evaluated and cytotoxic study on Michigan cancer foundation (MCF)-7 cancer cell line was studied.

Results and Discussion: The scanning electron microscope results of the optimized formulation showed spherical shaped vesicles. The ex vivo permeation of invasomes and the skin deposition (73\%) were studied on male Wistar rat skin. Cell line studies on MCF-7 cells showed cytotoxic effect of optimized formulation at $5 \mu 1 / \mathrm{ml}$.

Conclusion: It was concluded that the developed anastrozole invasomes enhanced the transdermal flux and the results obtained encouraged the use of the anastrozole invasomal gel for the potential treatment of breast cancer in post-menopausal women.
\end{abstract}

\section{INTRODUCTION}

Breast cancer tumors are hormone-receptor-positive in nature and require long-term adjuvant hormonal therapy and are the second most common cancer that causes the death among women (Bao and Rudek, 2011; Miller, 2003). Several alternative approaches to avoid systemic effects on usage of oral medicines were tried and researched. A novel approach of transdermal delivery with a vesicular system (invasomes) was tried and evaluated to deal with issues associated with oral administration.

Success of transdermal drug delivery is possible only when sufficient quantity of drug penetrates through the skin at a (desired) rate to achieve therapeutic effect (desired pharmacological response).

\section{"Corresponding Author}

P. K. Lakshmi, Department of Pharmaceutics, G. Pulla Reddy College of Pharmacy, Mehdipatnam, Hyderabad, India.

E-mail:drlakshmisuresh@gmail.com
The outer most layer of the human skin stratum corneum (SC) is the major barrier to the exogenous substances that include the drugs. One of the prevalent approaches is to reversibly decrease the barrier function of the skin with the help of physical or chemical penetration enhancement techniques (Kalpana and Lakshmi, 2013).

Invasomes are novel vesicle containing terpenes which help in enhancing the skin penetration compared to the conventional liposomes (Aqil et al., 2007). These are soft and elastic liposomal vesicles having high membrane fluidity, containing terpene and ethanol which acts as penetration enhancers and make them unique (due to their improved drug efficacy, enhancing patient compliance and comfort) (Singla et al., 2011; Williams and Barry, 2004). These vesicles are potential carriers with penetration enhancement properties of terpenes, thus promoting/enhancing drug delivery through skin (by altering the order of SC packing) (Cornwell and Barry, 1994; Williams and Barry, 2004). Terpenes are combinations of the isoprene units (Fox et al., 2011) derived from plant essential oils which have naturally occurring hydrocarbons. They were 
reported to have less toxicity, high percutaneous enhancement abilities, and low cutaneous irritancy at low concentrations $(1 \%-5 \%)$ (Dwibhashyam and Ratna, 2010). The effect of a specific terpene on skin depends upon its chemical structure and physicochemical properties, such as its lipophilicity, size and chirality, boiling point, energy of vaporization, and degree of unsaturation (Aqil et al., 2007; Prasanthi and Lakshmi, 2012). Many studies have already confirmed the ability of the terpenes for increasing the penetration either by disruption of SC lipids or by improving the partitioning of drug into SC or by interaction of intercellular proteins (Liu et al., 2013; Patel et al., 2011; Sammeta et al., 2011).

Anastrozole is a potent non-steroidal aromatase Type II inhibitor (AI) with ability to selectively inhibit aromatase. Aromatase acts on androstenedione inhibiting the conversion of estradiol to estrogen in peripheral tissues.

Therefore, aromatase inhibition leads to lower estrogen levels, leading to a decreased tumor mass or delayed progression of tumor growth in some women. Anastrozole has no noticeable effect on synthesis of adrenal corticosteroids, aldosterone, and thyroid hormone.

Common adverse reactions (occurring with an incidence of $\geq 10 \%$ ) in women taking oral anastrozole included: hot flashes, asthenia, arthritis, pain, arthralgia, hypertension, depression, nausea and vomiting, rash, osteoporosis, fractures, back pain, insomnia, headache, bone pain, peripheral edema, increased cough, dyspnea, pharyngitis, and lymphedema.

All ideal characteristics required for transdermal delivery of drug-like dosage of $1 \mathrm{mg}$ /day, solubility of $0.5 \mathrm{mg} / \mathrm{ml}$, partition coefficient of 3.5, molecular weight of 293.3 Daltons, and a half-life of 46.8 hours are in anastrozole.

This study was to explore the role of invasomes in increasing the transdermal penetration of anastrozole in the gel form to accomplish effective treatment for breast cancer in post-menopausal women. The optimized impact of formulated invasomes was studied by evaluating different variables of the invasomal properties using full factorial experimental design method.

The optimized invasomal formulation was then evaluated for morphological evaluation [scanning electron microscope (SEM)], particle size, drug entrapment efficiency, percentage skin deposition, and percentage drug release. Finally, the skin penetration ability of anastrozole-loaded invasomes was examined using ex vivo studies on male Wistar rats.

\section{MATERIALS AND METHODS}

\section{Material}

Anastrozole was obtained as a gift sample from Suven pharmaceuticals, Andhra Pradesh, soya phosphatidylcholine was purchased from Yarrow chem Mumbai, Phospholipon $80 \mathrm{H}$ and Phospholipon $90 \mathrm{H}$ from lipoid $\mathrm{GmbH}$, chloroform, and ethanol from S.D. Fine Chemicals Limited, Nerolidol, Geraniol, Fenchone, and Linalool from Alfa Aesar. Male Wistar rats and white rabbits were used with grant approved by the Institutional Animal Ethical Committee (IAEC) in G. Pulla Reddy College of Pharmacy Registration number 320/CPCSEA.

\section{Preparation of invasomes by thin film hydration method}

Conventional film hydration method was used for the preparation of the invasomes. Phospholipids were dissolved in ethanol:chloroform $(2: 1, \mathrm{v} / \mathrm{v})$ and the mixture was dried to generate a thin film by reducing the pressure from 500 to $1 \mathrm{mbar}$ at $45^{\circ} \mathrm{C}$ using rotary flash evaporator and placed under vacuum (1 mbar) for 24 hours. The film is hydrated (at lipid phase transition $45^{\circ} \mathrm{C}$ ) with a mixture of phosphate buffer ( $\mathrm{pH}$ : 7.4 ; phosphate buffer saline) containing ethanol, drug, and terpene for 30 minutes. The obtained vesicles were ultrasonicated and subsequently sized using polycarbonate membrane (Dragicevic-Curic et al., 2011; Haag et al., 2011; Kalpana and Lakshmi, 2013).

\section{Experimental design}

Full factorial design method was used to optimize the invasomal formulation. The technique of factorial design is an effective method of indicating the relative significance of several variables and their interactions. In this design, number of experiments required for studying the significance of variables and their interactions is dependent on the number of independent variables selected (Amit Prajapati et al., 2012).

A $2^{3}$ randomized full factorial design was utilized in the present study. In this study, three factors were evaluated each at two levels, and experimental trials were carried out with eight possible combinations. Table 1 shows design layout and coded value of independent factors selected based on preliminary study. Lipids, quantity of lipids, and percentage of terpene were selected as independent variables, while entrapment efficiency for eight combinations was selected as dependent variables. Table 2 shows full factorial design experimental run formulae and Table 3 shows the formulation of the factorial batches (F1-F8).

The dissolution data of factorial formulations F1-F8 are shown in polynomial equation. $2^{3}$ full factorial designs equation is:

$$
\begin{aligned}
Y= & B 0+B 1(x 1)+B 2(x 2)+B 3(x 3)+B 12(x 1 \times 2) \\
& +B 13(x 1 \times 3)+B 23(x 2 \times 3)+B 123(x 1 \times 2 \times 3)
\end{aligned}
$$

Where $Y$ is dependent variable, $B 0$ arithmetic mean response of eight batches, and $B 1$ estimated coefficient for factor $X 1$. The main effects $(X 1, X 2$, and $X 3)$ represent the average result of changing one factor at a time from its low to high value. The interaction term $(X 1, X 2$, and $X 3)$ shows how the response changes when three factors are simultaneously changed. The polynomial terms $\left(X 1^{2}, X 2^{2}\right.$, and $\left.X 2^{3}\right)$ were included to investigate nonlinearity.

The work was further extended by studying the combination effect of invasomes with gel which helps in the ease of application. The invasomal gel was compared with the effect of plain gel with different concentrations of terpene.

Table 1. Selection of independent variables for a 23 randomized full factorial design.

\begin{tabular}{lcc}
\hline & \multicolumn{2}{c}{ Levels } \\
\cline { 2 - 3 } Factors (independent variable) & $\mathbf{- 1}$ & $\mathbf{+ 1}$ \\
\hline Lipid (factor A) & Phospholipon $80 \mathrm{H}$ & Soya lecithin \\
Quantity of lipid (factor B) & 200 & 300 \\
Percentage of terpene (factor C) & 2.5 & 4 \\
\hline
\end{tabular}


Table 2. Full factorial design experimental run formulae.

\begin{tabular}{clcc}
\hline Trials & Factor A & Factor B & Factor C \\
\hline 1 & Soya lecithin & 2 & 4.0 \\
2 & Phospholipon 80 H & 3 & 4.0 \\
3 & Phospholipon 80 H & 2 & 4.0 \\
4 & Soya lecithin & 2 & 2.5 \\
5 & Phospholipon 80 H & 2 & 2.5 \\
6 & Soya lecithin & 3 & 4.0 \\
7 & Soya lecithin & 3 & 2.5 \\
8 & Phospholipon $80 \mathrm{H}$ & 3 & 2.5 \\
\hline
\end{tabular}

Note: Factor A: Lipid; Factor B: Percentage of lipid; Factor C: Percentage of terpene.

Table 3. Entrapment efficiency of the optimized formulation.

\begin{tabular}{llc}
\hline FC & Stability, microscopic analysis & \%EE \\
\hline F3 & Stable formulation, vesicles are abundantly seen & 66.4 \\
F8 & Stable formulation, vesicles are abundantly seen & 57.64 \\
\hline
\end{tabular}

\section{Characterization and evaluation of invasomes}

\section{Drug-excipient compatibility study by FTIR}

The spectrum analysis of anastrozole, lipids, and terpenes which were used in the preparation of invasomes was studied by Fourier transform Infra-red (FTIR) spectroscopy. FTIR spectra were recorded by preparing potassium bromide $(\mathrm{KBr})$ disks using a Shimadzu Corporation (Kyoto, Japan) facility (model-8400S). Potassium bromide $(\mathrm{KBr})$ pellets were prepared by mixing drug with potassium bromide by compacting in a hydrostatic press under vacuum at 6-8 tons pressure. The IR spectrum of resultant pellet was recorded from 4,000 to $200 \mathrm{~cm}^{-1}$. The spectrum was then observed for the presence of characteristic peaks for the respective functional group in the compound.

\section{Entrapment efficiency}

Invasomes formulation of about $1.5 \mathrm{ml}$ was transferred into Eppendorf tubes. It was then centrifuged for 30 minutes at $4^{\circ} \mathrm{C}$ at $8,000 \mathrm{rpm}$ for two cycles, followed by 15 minutes at 6,000 rpm for one cycle to separate anastrozole containing invasomes from free drug. The clear fraction was used for the determination of un-entrapped drug using the following formulae.

$$
\text { Entrapment Efficiency } \%=\frac{\text { Amount of Entrapped Drug }}{\text { Amount of total drug added }} \times 100
$$

\section{Microscopy}

The invasomal dispersion was suitably diluted and put on a glass slide and then viewed under the microscope. Scanning electron microscope (SEM) was performed for the optimized formulation for determining surface morphology, size, and shape of the formulation.

\section{Particle size and surface charge}

The formulation was diluted 1,000-fold with water before the measurement to ensure that the light scattering intensity is within the instruments' sensitivity range. The particle size and zeta potential were measured at $25^{\circ} \mathrm{C}$ using the light-scattering by Malvern Zetasizer. The polydispersity index was used to measure the size distribution. Measurement was performed in triplicates and the mean values obtained were recorded (Verma and Fahr, 2004; Verma et al., 2003).

\section{Ex vivo diffusion studies and skin deposition studies}

The protocol of the study was approved by the IAEC. Male Wistar rats of about $200 \mathrm{~g}$ were euthanized. The fur on the ventral side of the rat was removed by a depilatory, and then the skins were excised and stored at $-20^{\circ} \mathrm{C}$. Before the experiment, skin was taken out and left to defrost at room temperature, washed, and mounted on top of the diffusion cells and left to hydrate for 1 hour before the application of the formulation.

\section{General procedure}

The permeation of invasomal formulation was determined using Franz (vertical) diffusion cell. The effective diffusion area of the cell was $4.9 \mathrm{~cm}^{2}$ and the receptor volume was $50 \mathrm{ml}$. The skin was mounted with the SC facing the receptor compartment with $50 \mathrm{ml}$ of $7.4 \mathrm{pH}$ saline phosphate buffer at $600 \mathrm{rpm}$ and at $37^{\circ} \mathrm{C} \pm$ $0.5^{\circ} \mathrm{C}$. The donor compartment maintained at $32^{\circ} \mathrm{C} \pm 0.5^{\circ} \mathrm{C}$ was applied with the invasomal formulation. At appropriate intervals, $5 \mathrm{ml}$ of aliquots was withdrawn from the receptor compartment and immediately replaced by an equal volume of fresh solution. The samples were analyzed by UV spectrophotometric method at $210 \mathrm{~nm}$. Ex vivo permeation rate studies such as percentage drug release, steady-state transdermal flux (SSTF0), and skin deposition were estimated for different formulations (F3, F8). The ex vivo permeation studies were replicated three times and results are presented as mean values $(n=3 \pm \mathrm{SD})$.

\section{Skin deposition studies}

Skin deposition studies were performed in order to determine the amount of anastrozole retained in the skin. At the end of permeation studies (eighth hour), the skin was left in ethanol for overnight. Measurable skin sample was homogenized with ethanol for 5 minutes and the resulting solution was centrifuged at $6,000 \mathrm{rpm}$ for 15 minutes and the supernatant was analyzed using UV-1800 spectrophotometer at $210 \mathrm{~nm}$.

\section{Preparation of invasomal gel}

Gels were prepared by using sodium carboxy methyl cellulose (CMC) (5\%), propanol $(3 \mathrm{ml})$, propylene glycol $(1 \mathrm{ml})$, and distil water up to $10 \mathrm{~g}$. Measured quantity of propanol and propylene glycol was added to overnight soaked Sodium CMC and stirred continuously. Required amount of water was added until the gel weighs $10 \mathrm{~g}$. To this gel, $10 \mathrm{mg}$ of invasomes was added and stirred continuously to form a homogenous mixture.

For non-invasomal gels, anastrozole (10 mg) with $2.5 \%$ and $4 \%$ of terpene (fenchone) was added and stirred continuously to form a homogeneous mixture. Gel equivalent to $1 \mathrm{mg}$ of drug was taken for further studies.

\section{Characterization and evaluation of invasomal gel}

\section{Determination of $p H$}

The $\mathrm{pH}$ of anastrozole invasomal gel formulations was determined using digital $\mathrm{pH}$ meter. One gram of gel was dispersed in $100 \mathrm{ml}$ of distilled water and stored for 2 hours at constant temperature. $\mathrm{pH}$ was measured in triplicate and average values were calculated. 


\section{Drug content}

Anastrozole content in invasomal gel was measured by dissolving $1,000 \mathrm{mg}$ of gel in $10 \mathrm{ml}$ solvent (ethanol) by sonication. Then $1 \mathrm{ml}$ of this solution was transferred to $10 \mathrm{ml}$ volumetric flask and buffer solution was added to volume. Absorbance of anastrozole was measured at $210 \mathrm{~nm}$ in UV-1800 spectrophotometer after filtering the solution through the Whatman filter paper no. 42. The experiment was repeated thrice, and average values were calculated (Acharya et al., 2016).

\section{Homogeneity}

It was determined by visual inspection for the appearance of gel and presence of any aggregates (Barhate et al., 2011).

\section{Extrudability}

Fifteen grams of gel was taken in Pfizer hardness tester and plunger was adjusted. $1 \mathrm{~kg} / \mathrm{cm}^{2}$ pressure was applied for 30 seconds and then quantity of gel extruded was weighed. This procedure was repeated three times at three equidistance places of tube (Lakshmi et al., 2014).

\section{Spreadability}

The spreadability of the gel was determined by calculating the spreading diameter of $1 \mathrm{~g}$ of gel between $20 \times 20 \mathrm{~cm}$ glass plates after 1 minute. The mass of the upper plate was standardized at $150 \mathrm{~g}$ (Lakshmi et al., 2014).

The spreadability was calculated by using the formula Where

$$
S=\frac{m l}{t}
$$

$S=$ spreadability

$m=$ weight on upper glass slide

$l=$ length of the glass slide

$t=$ time taken in seconds

\section{Determination of viscosity}

Viscosity of prepared gels was determined by VISCO lab 3000 viscometer that provides viscosity and temperature readings, respectively. Sample size of around 1-2 ml was applied on the sensor in the chamber, results of which were displayed on the screen. Determination was done in triplicates and the average was calculated. Ex vivo studies and skin deposition studies were performed even for the invasomal gel (Refer to "Ex vivo diffusion studies and skin deposition studies").

\section{Release kinetic studies-pattern and mechanism}

The release patterns and mechanism are described by various linear and non-linear kinetic models that are dependent on the curve fitting procedure. Linear models include zero order, Higuchi, Hixson-Crowell and non-linear models include first order, Weibull, and Korsmeyer-Peppas. The dissolution profile of all the four formulations were subjected to zero-order, first-order, Higuchi, and Korsmeyer-Peppas models to ascertain the kinetic modeling of drug release.

\section{Skin irritation studies}

Skin irritation studies were performed by using control, placebo, and test formulation by applying on the left and right dorsal surface of rabbit skin and changes were observed for 72 hours. The irritation impact of the samples on the rabbit skin (erythema and edema) was observed and score was given according to the Primary Dermal Irritation Index Classification.

\section{Stability studies}

The optimized formulation was evaluated for physical stability to investigate the leaching of the drug from the vesicles. The invasomal gel sample was sealed in two $10 \mathrm{ml}$ ointment tubes, of which one was stored in the refrigerator at a temperature of $4^{\circ} \mathrm{C}-8^{\circ} \mathrm{C}$ and second one at $27^{\circ} \mathrm{C}-30^{\circ} \mathrm{C}$ (room temperature) for 1 month. The appearance, drug content, and viscosity of the samples were determined every week.

\section{Cell-line studies}

Cancer is a multi-factorial and multistep disease caused by the accumulation of multiple hits which involves genetic alterations leading to initiation, progression, and promotion of carcinogenesis. Hence, cancer cell lines are frequently used as in vitro tumor models.

The cancer cell line human malignant breast adenocarcinoma [Michigan cancer foundation (MCF)-7] originally sourced from American Type Culture Collection was sub-cultured in-house in VIPER-CMCR based in Hyderabad-India. Cells were grown in $75 \mathrm{~cm}^{2}$ bottle canted necked vented flasks (Corning) with Dulbecco's Modified Eagles medium (Gibco Invitrogen, Paisley, UK) and were maintained in a humidified atmosphere of $5 \% \mathrm{CO}_{2}$ at $37^{\circ} \mathrm{C}$. Cells (passages $30-50$ ) were supplemented with $10 \%$ fetal bovine serum, $1 \%$ non-essential amino acids, $1 \%$ penicillin $(1,000$ $\mathrm{U} / \mathrm{ml}), 1 \%$ streptomycin $(1,000 \mu \mathrm{g} / \mathrm{ml})$, and $1 \%$ amphotericin (250 U/ml). The cells were passaged enzymatically with $0.25 \%$ trypsin - $1 \mathrm{mM}$ ethylene diamine tera acetic acid and sub-cultured on $75 \mathrm{~cm}^{2}$ plastic flasks at a density of $2.2 \times 104 \mathrm{cells} / \mathrm{cm}^{2}$. Culture medium was replaced every 2 days. Cell confluence $(80 \%)$ was confirmed by microscopic observance. Treatment was performed 12 hours post-seeding to prevent cell differentiation.

\section{RESULTS AND DISCUSSION}

\section{Characterization and evaluation}

Drug-excipient compatibility studies

Compatibility of anastrozole with excipient was studied by FTIR (FTIR 8400s, Shimadzu, Japan) in the range of 4,000-400 $\mathrm{cm}^{-1}$ using potassium bromide pellet method. Pure anastrozole showed absorption peaks at 3,045.9-3,055 representing aromatic $\mathrm{C}-\mathrm{H}$ stretch of benzene, 2,234.5-2,244 representing aliphatic $\mathrm{C} \equiv \mathrm{N}$ stretch of nitrile, 1,615-1,604 and $1,280-1,272$ representing $\mathrm{C}=\mathrm{N}$ hetero aromatic stretching, and 3,444-3,432 representing aromatic nitrile.

The FTIR spectra of formulation with terpenes and phospholipids reveal no interaction between drug and excipient; both the drug and excipient peaks were identified and interpreted in the spectra. The spectra confirmed the absenteeism of any chemical interaction between the drug, terpene, and phospholipids (Fig. 1).

\section{Entrapment efficiency}

Drug entrapment evaluates the potential of drug delivery into the system which is an important parameter. The entrapment 
of anastrozole within the formulation was evaluated to investigate the influence of invasomal composition, i.e., type of lipid used, quantity of lipid used, and percentage of terpene used, on the drug loading capacity. As shown in Figure 3, the type of lipid and the quantity of the lipid used for invasomes preparation influenced the entrapment efficiency of the colloidal carrier. Phospholipon $80 \mathrm{H}$ was found to have better entrapment efficiency than soya lecithin.

Related to quantity of lipid used, entrapment efficiency was observed at $200 \mathrm{mg}$ and it decreased with further increase in the quantity of phospholipid. Related to percentage of terpenes, entrapment efficiency increased with higher percent of terpene. Figure 2 gives the percentage entrapment efficiency.

\section{Analysis of factorial design}

Factorial design analyzes the combined effect of different independent variables of the prepared invasomes. The data were plotted on main effect plots to assess the relationship between the dependent and independent variables, while interaction plots were used to show the relationship between the response in relation to dependency of two independent variables.

It is inferred that there is inter-relationship between independent variables and its response as the plotted lines are not parallel to $x$-axis and the response value is not the same for all

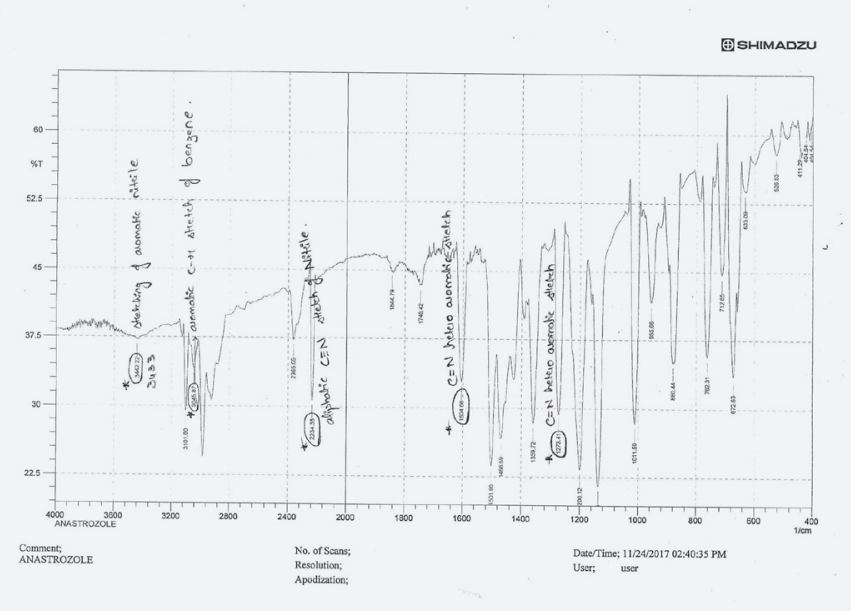

(A)

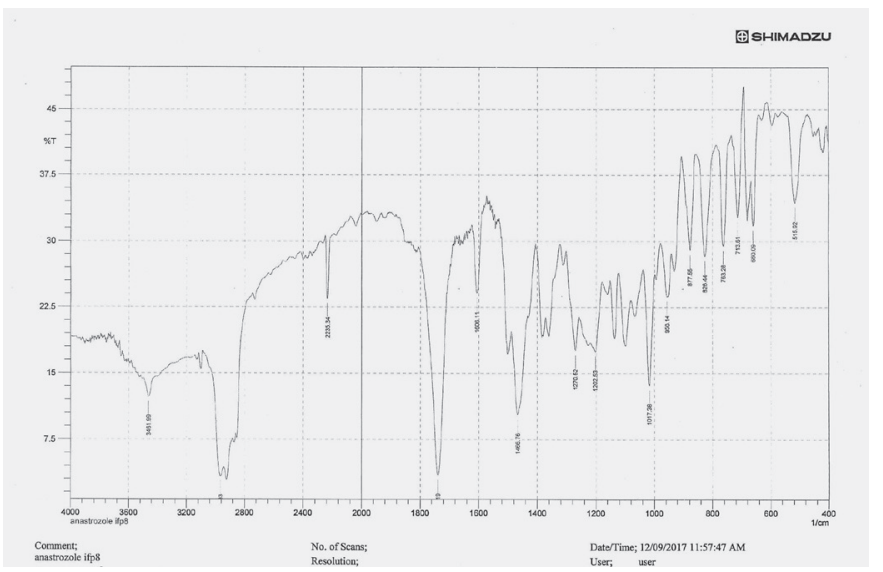

(B)

Figure 1. (A) FTIR of pure drug of anastrozole and (B) FTIR of optimized formulation. independent variables. The magnitude of inter-relationship effect is high as the slope of the line is steeper (Fig. 3A).

Interaction plots (Fig. 3B) with data obtained show interaction between type of lipid and quantity of lipid used while there was no interaction in other independent variables.

\section{Microscopy of invasomal formulation}

Surface morphology and the three-dimensional nature of the invasomes studied through SEM (Fig. 4) confirmed the preparation as smooth-surfaced having vesicular characteristics.

The formulation had smooth and deformed vesicles which are beneficial for transdermal application, as per previous studies (Maghraby et al., 2001).

\section{Particle size and zeta potential of invasomal formulation}

The vesicles had a diameter of $226.4 \pm 53.19 \mathrm{~nm}$ and had polydispersity index of 0.540 , Figure 5 indicating that the optimized formulation is polydisperse in nature. The particle size analysis revealed that the invasomes were of nanosize which is ideal for the transdermal delivery of the drug (Maghraby et al., 2003; Dragicevic-Curic et al., 2008).

Zeta potential was measured at Indian Institute of Chemical Technology, Hyderabad, India, using Malvern zeta sizer and was found to be $-20.9 \mathrm{mV}$. Negative charge on the particle may be due to the presence of ethanol in the sample preventing vesicle aggregation due to electrostatic repulsion, thus ensuring stability of invasomal dispersion (Badran et al., 2012; Dragicevic-Curic et al., 2008; Paradkar et al., 2004).

\section{Ex vivo drug diffusion studies}

Permeation studies were performed on excised male Wistar rat abdominal skin using Franz diffusion cell method.

Anastrozole in combination with fenchone had increased entrapment efficiency and penetration. While earlier research studies have concluded higher entrapment efficiency for lipophilic drug found using a terpene with high lipophilicity (Mura et al., 2009). The results seen with dapsone, a lipophilic drug with highly lipophilic terpene (limonene and cineole) (El-Nabarawi et al., 2018), finasteride with limonene and cineole (Prasanthi and Lakshmi, 2013). Besides, this study results can

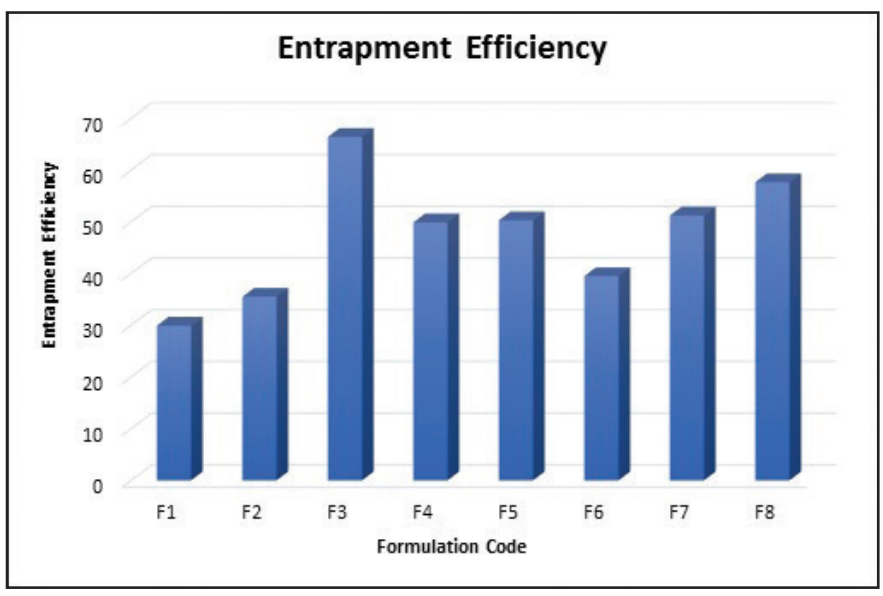

Figure 2. Percentage entrapment efficiency of all the formulations. 


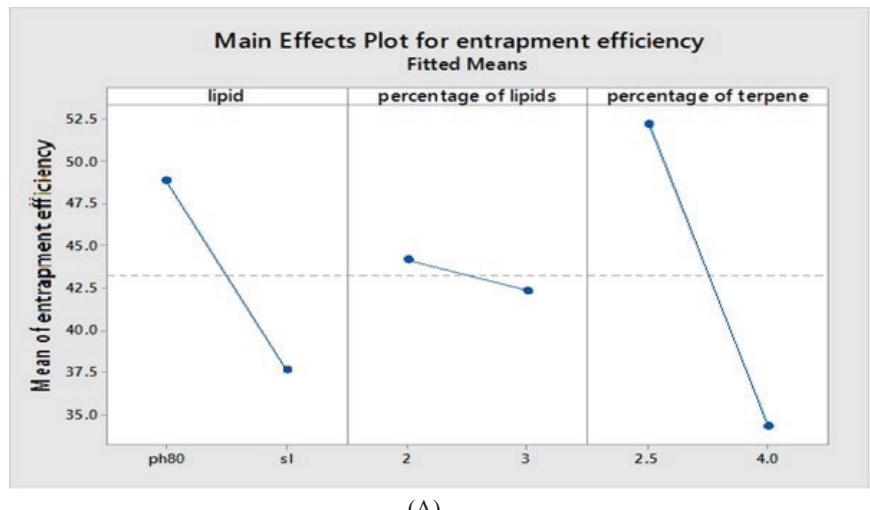

(A)

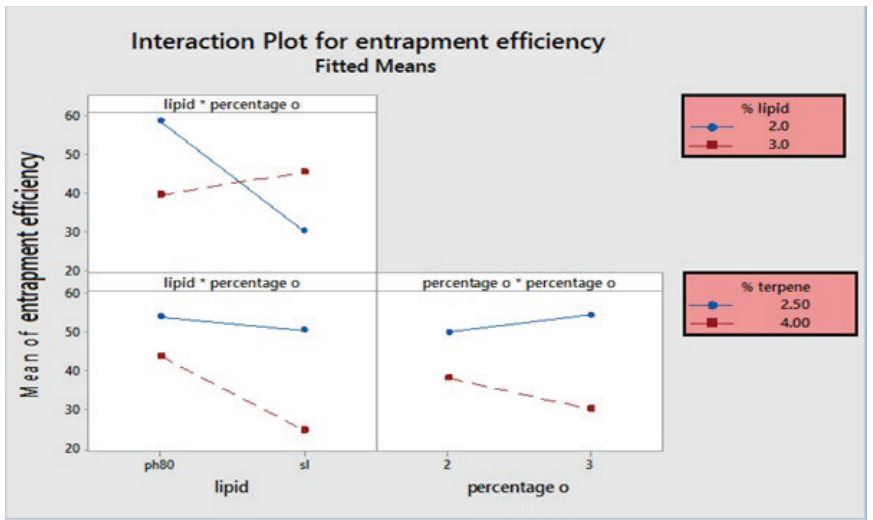

(B)

Figure 3. (A) Main effect plot and (B) interaction plot.

be inferred as anastrozole being a hydrophilic drug has higher entrapment efficiency when combined with fenchone having lower lipophilicity ( $\log P$ of fenchone being 2.13).

The higher enhancement of fenchone may also be attributed to its low lipophilicity, low boiling point, and high concentration. Low boiling point of terpenes indicates the weak cohesiveness or self-association of the molecules and therefore easily associate with lipid components of SC altering the barrier property (Bilek et al., 2009).

Invasomes containing $4 \%$ of terpene showed a significantly higher entrapment efficiency, enhanced penetration, and accumulation of anastrozole in the skin compared to the drug without vesicles. This can be due to the high repulsion force between the lipophilic composition of the vesicular system and the hydrophilic terpene.

Entrapment efficiency was increased as the volume of phospholipid (Phospholipon $80 \mathrm{H}$ ) increased to some level and it was decreased though the volume of phospholipid was increased. This was due to the hydrophilic nature of the phospholipid (Latha et al., 2017; Ravi et al., 2012).

F3 showed $52.31 \pm 0.07$ percentage drug release and percentage skin deposition of $46.96 \%$ (i.e., $95.83 \mu \mathrm{g} / \mathrm{cm}^{2}$ ), whereas F8 showed $68.08 \pm 0.05$ percentage of drug release and percentage skin deposition of $30.34 \%\left(61.93 \mu \mathrm{g} / \mathrm{cm}^{2}\right)$. Results are summarized in Table 4. In the present study, percentage skin deposition of F8 formulation increased by 7.12-fold, while F3 formulation increased by 11.18 -fold (with just $52.31 \pm 0.07$ percentage drug release) while pure drug skin deposition percentage value stands

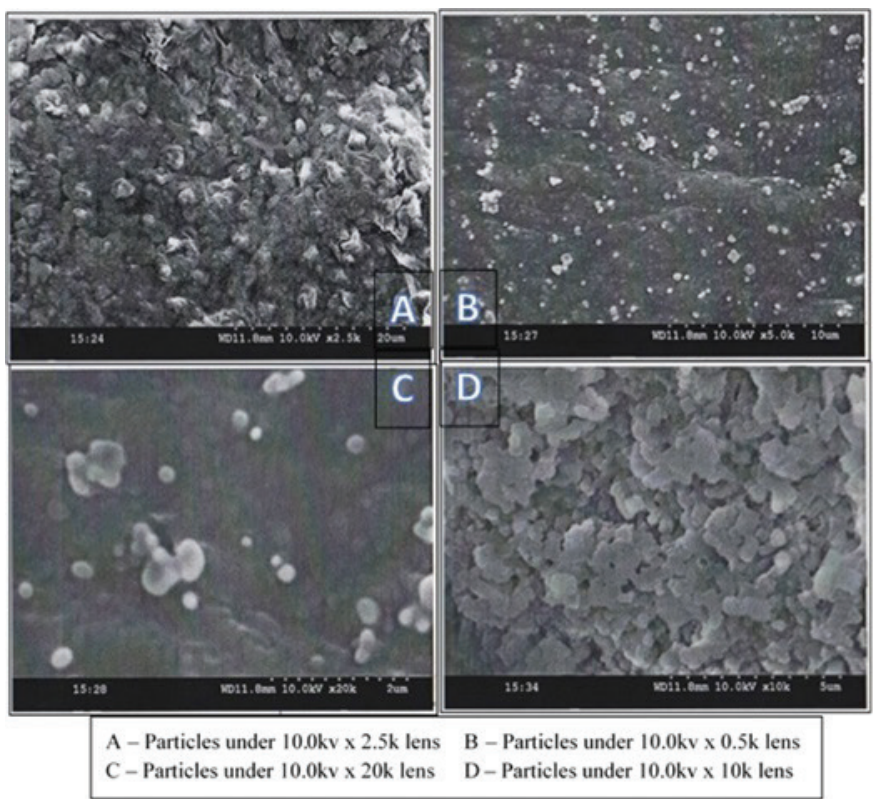

Figure 4. SEM microscopic images of invasomal formulation.

at $4.26\left(8.74 \mu \mathrm{g} / \mathrm{cm}^{2}\right)$. Hence, F3 formulation was selected for the further evaluation.

Based on these results, the penetration enhancement mechanism of phospholipids, ethanol, and terpenes was also considered. These prospects are in accord with the outcomes found by other authors who proposed that ethanol and phospholipids when applied together have an additive effect of fluidizing the intercellular SC lipids, which results in an enhanced penetration of substances (Verma et al., 2004). Upon application to the skin, ethanol used in the invasomes fluidizes and disturbs the organization of the bilayer structure of the intercellular lipid matrix of SC, resulting in enhanced penetration (Upadhyay et al., 2011). Also, there might be a possibility that, a part of the vesicle might get fragmented during the penetration which may be due to terpene, as well as phospholipid could have acted as penetration enhancer fluidizing the intracellular lipids (Kalpana and Lakshmi, 2013; Kirjavainen et al., 1996).

The release of the drug into the deeper layers of the $\mathrm{SC}$ is based on the phenomena that the disturbed organization of the SC lipids and the presence of the transepidermal osmotic gradient might facilitate the penetration of the invasomes (Cevc and Blume, 1992) (with high deformability property) aiding in the release of the incorporated drug along the penetration pathway. (Dragicevic-Curic et al., 2008). Some earlier studies reported that small invasomes pass through hydrophilic channels present in the intercellular spaces of SC or through follicular transport pathway and reach deeper layers of SC (DragicevicCuric et al., 2008).

The theory that vesicles disintegrate at the skin surface and components penetrate molecularly into the intercellular lipid matrix and mix with the SC lipids modifying the lamellae thereby enhancing the drug penetration was also proposed (Zellmer et al., 1995). The study and results found by the above-mentioned groups support the outcome of this study that some invasomes were fragmented during their penetration through the 


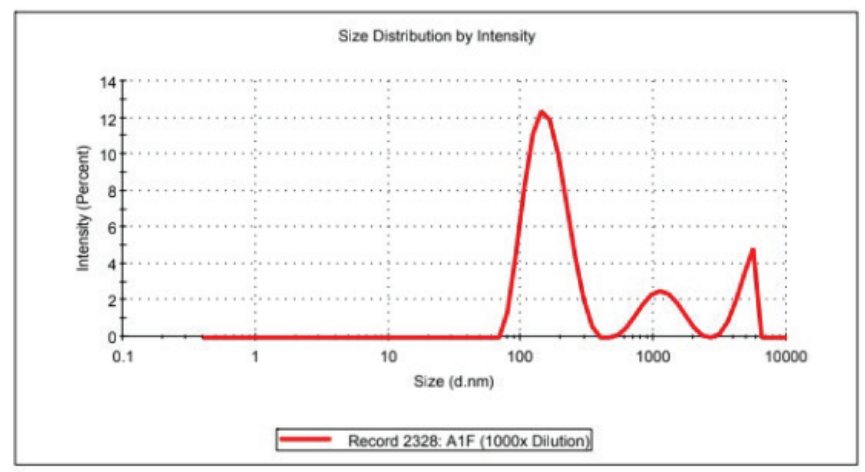

(A)

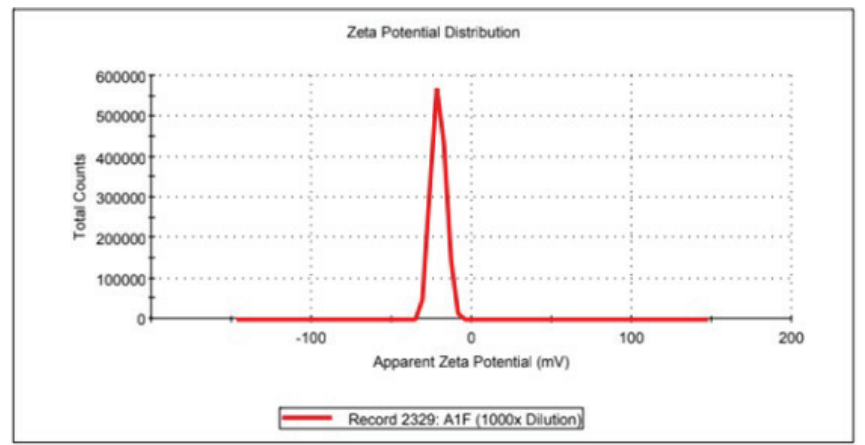

(B)

Figure 5. (A) Average particle size and size distribution measurement and (B) Zeta potential determination.

Table 4. Ex vivo release permeation data.

\begin{tabular}{lcccc}
\hline $\begin{array}{l}\text { Formulation } \\
\text { code }\end{array}$ & $\begin{array}{c}\text { Q8 } \\
(\%)\end{array}$ & $\begin{array}{c}\text { SSFT } \\
\left(\boldsymbol{\mu g} / \mathbf{c m}^{2} / \mathbf{h o u r}\right)\end{array}$ & $\mathbf{E E}$ & $\begin{array}{c}\text { \%Skin } \\
\text { deposition }\end{array}$ \\
\hline F3 & $52.31 \pm 0.07$ & 0.0082 & 66.4 & 46.9615 \\
F8 & $68.08 \pm 0.05$ & 0.0104 & 57.64 & 30.3462 \\
Drug solution & $10.96 \pm 0.03$ & 0.0014 & -- & 4.2692 \\
\hline
\end{tabular}

Note: SSTF: study state transdermal flux; EE: entrapment efficiency.

SC while some small deformable invasomes have penetrated to the deeper SC layer intact. However, the mechanism of the penetration enhancing ability of invasomes should be further investigated.

\section{Invasomal gel of anastrozole}

From the ex vivo diffusion results, it is concluded that the F3 formulations has better penetration effect compared to F8 formulation. Since direct application of the invasomal solution is difficult, it was incorporated into sodium CMC gel to ease the application process. Penetration values of invasomal gel, control gel, and gel containing $2.5 \%$ and $4 \%$ of terpene alone (devoid of ethanol) were studied for comparison.

Permeation studies were conducted using excised male Wistar rat abdominal skin using Franz diffusion cell. Cumulative percentage drug release after 8 hours of application was found to be $26.35 \% \pm 0.08 \%$ for F3 invasomal gel when compared to $68.77 \% \pm 0.05 \%$ of $4 \%$ of terpene gel (AFG4), $59.81 \pm 0.08$ of $2.5 \%$ of terpene gel (AFG2.5), which was greater than the control gel $(24.38 \pm 0.01)$. Many literatures confer the increase in the permeation with terpene loaded vesicles when compared

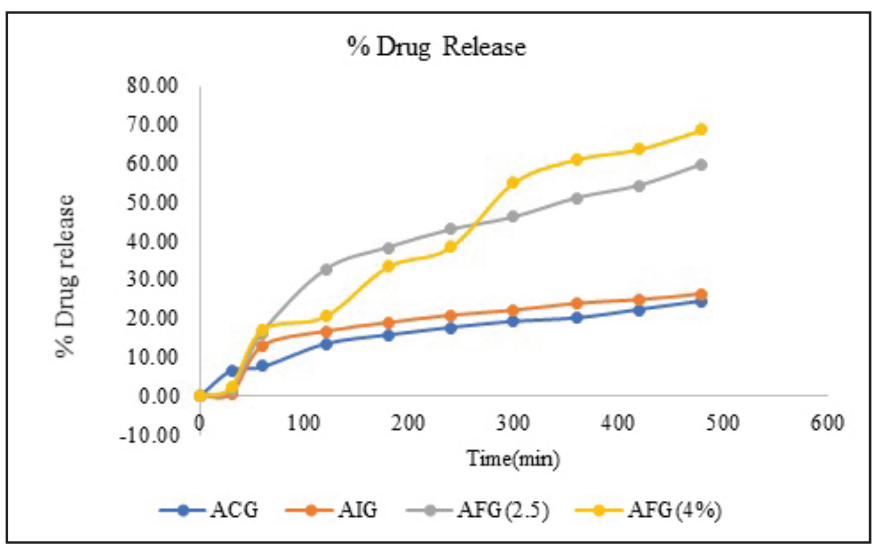

Figure 6. Percentage drug release of the optimized formulation with the controls.

with liposomal vesicles. Improved permeation of formulation with terpenes than conventional liposomes may be attributed to synergistic effect of the terpenes (Lakshmi et al., 2014; Verma et al., 2004). Figure 6 gives the percentage drug release of the optimized formulation with control.

The highest ex vivo deposition amount of anastrozole was found to be 149.2 versus $24.33 \mu \mathrm{g} / \mathrm{cm}^{2}$ for $\mathrm{AFG} 2.5$ and $31.39 \mu \mathrm{g} / \mathrm{cm}^{2}$ (AFG4), followed by control gel having $11.38 \mu \mathrm{g} /$ $\mathrm{cm}^{2}$ representing about 13.11-fold higher for the drug-loaded invasomes compared to the control gel. Invasomes are known to be efficient vesicular drug carrier system for delivering both hydrophilic and lipophilic drugs (Aqil et al., 2007).

In addition, by the incorporation of fenchone, an efficient delivery system was developed which helps in the greater and effective penetration of the drug through the skin. The results reveal that the skin retention of anastrozole is enhanced using invasomes and are in accord with the outcomes obtained by other researchers who suggested that ethanol (Verma et al., 2004), phospholipids, and terpenes applied together have a synergistic effect on fluidizing the intercellular SC lipids. The other evaluation parameters are summarized in Table 5.

\section{Kinetic modeling}

Control gel followed zero order kinetics, while control gel with $2.5 \%$ and $4 \%$ terpene was found to follow first-order kinetics with Higuchi model dependent kinetics.

First-order kinetics behavior of prepared invasomal gel with Higuchi model dependent kinetics might be due to the complex nature of the formulation, which is a sandwich model having reservoir system incorporated in matrix system.

\section{Cell-line studies}

MCF-7 cells were treated 12 hours post-seeding with 2.5 and $5 \mu \mathrm{l} / \mathrm{ml}$ concentration of each formulation, namely AIG and AIS for morphological study. Cells were observed for 24, 48, and 72 hours after treatment of test formulations. Images were taken by Axiovert 200M phase contrast microscope at the magnification of $10 \times$. Axiovision Rel.4.2 software was used to acquire the images. Figure 7 shows the results of the cell line studies. 
Table 5. Physico chemical evaluation.

\begin{tabular}{|c|c|c|c|c|c|c|c|c|c|}
\hline $\begin{array}{l}\text { Formulation } \\
\text { Code }\end{array}$ & $\begin{array}{l}\text { Lag time } \\
\text { (minute) }\end{array}$ & $\underset{\left(\mu \mathrm{g} / \mathrm{cm}^{2} / \text { minute }\right)}{\text { Flux }}$ & $\begin{array}{l}\text { Permeability } \\
\text { coefficient } \\
(\mathrm{cm} / \text { minute })\end{array}$ & $\begin{array}{c}\text { \%Skin } \\
\text { deposition }\end{array}$ & Drug content & pH & Homogeneity & Extrudability & $\begin{array}{l}\text { Spreadability } \\
\text { (g.cm/second) }\end{array}$ \\
\hline ACG & $28 \pm 0.02$ & 0.0349 & $1.36 \times 10^{-4}$ & 5.57 & $95.5 \pm 0.3$ & $7.01 \pm 0.6$ & ++ & ++ & $20.1 \pm 0.01$ \\
\hline $\operatorname{AFG}(2.5 \%)$ & $33 \pm 0.03$ & 0.2461 & $9.84 \times 10^{=4}$ & 11.92 & $96.7 \pm 0.81$ & $7.01 \pm 0.6$ & ++ & ++ & $20.3 \pm 0.54$ \\
\hline AFG $(4 \%)$ & $35 \pm 0.05$ & 0.3046 & $12.6 \times 10^{=3}$ & 15.38 & $98.0 \pm 0.4$ & $7.05 \pm 0.3$ & +++ & ++ & $20.4 \pm 0.04$ \\
\hline AIG & $25 \pm 0.04$ & 0.1034 & $41.36 \times 10=4$ & 73.11 & $98.2 \pm 0.2$ & $7.07 \pm 0.02$ & +++ & +++ & $20.6 \pm 0.02$ \\
\hline
\end{tabular}

Note: ACG: Anastrozole control gel; AFG (2.5\%): Anastrozole gel with 2.5\% of fenchone; AFG (4\%): Anastrozole gel with 4\% of fenchone; AIG: Anastrozole invasomal gel.

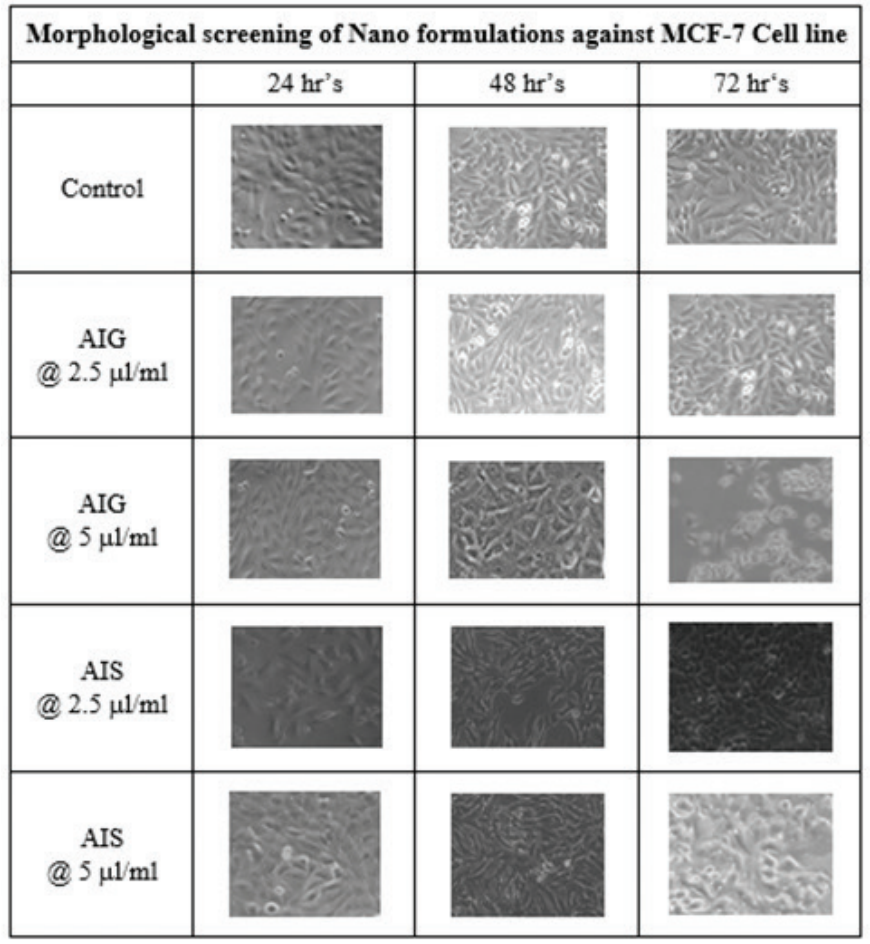

Figure 7. Results of cell line studies.

\section{Observable effect}

Treatment of AIG@ @ $5 \mu \mathrm{l} / \mathrm{ml}$ and AIS@ $5 \mu \mathrm{l} / \mathrm{ml}$ showing considerable cytotoxic effect against MCF-7 Cell line at 72 hours. Additional studies such as in vivo studies and $\mathrm{IC}_{50}$ study of each sample are required to investigate further activity analysis of the invasomal formulation of anastrozole.

\section{Skin irritation and stability}

Skin irritation studies: Skin irritation studies were conducted on depilated rabbit skin and reaction at the site of application was assessed and scored according to Draize method. No indications of erythema and edema were observed even after 72 hours of the study.

The stability studies were conducted for 1 month at room temperature and in the refrigerating temperature. The AIG formulation was found to be stable in refrigerating condition. By the end of fourth week, the appearance of the formulation was observed to be excellent with drug content of $98.42 \% \pm 1.02 \%$ and viscosity of $18,000 \pm 510 \mathrm{cps}$ at refrigerating temperature. There was a considerable decrease of about $10 \%$ in the drug content when the formulation was stored in the room temperature. Hence, it can be concluded that the formulation was stable at refrigerating condition.

\section{CONCLUSION}

In the present study, invasomes were studied as a possible carrier for transdermal delivery of anastrozole since side effects were reported with oral anastrozole administration in breast cancer patients. It can be a preferred transdermal delivery system due to its ideal transdermal properties. Unique advantages of transdermal and vesicular system are exploited to enhance the deposition of anastrozole at adipose tissue and to avoid systemic entry. The morphological screening of nanoformulations on MCF-7 cell line showed that both the suspension and anastrozole invasomal gel showed the cytotoxic activity. Hence, it can be concluded that the invasomal gel has effective site-specific and cytotoxic activity. This result demonstrates that the skin deposition characteristic of anastrozole can be improved using invasomes for targeted drug action in order to overcome the issues related to oral administration of the drug in treating breast cancer in postmenopausal women.

\section{REFERENCES}

Acharya A, Dhakal P, Khadka D. Formulation and evaluation of transdermal gel of lornoxicam and its delivery by passive and iontophoresis method: a comparative study. Int J Pharm Sci Res, 2016; 7(2):810-8; doi:10.13040/IJPSR.0975-8232.7(2).810-18.

Aqil M, Ahad A, Sultana Y, Ali A. Status of terpenes as skin penetration enhancers. Drug Discov Today, 2007; 12:1061-7.

Bao T, Rudek MA. The clinical pharmacology of anastrozole. Eur Oncol Haematol, 2011;7(2):106-8; doi:10.17925/ EOH.2011.07.02.106.

Barhate SD, Potdar MB, Nerker P. Development of meloxicam sodium transdermal gel. Int J Pharm Res Dev, 2010; 2:1-7.

Bilek $\mathrm{H}$, Wonglertnirant $\mathrm{N}$, Ngawhirunpat $\mathrm{T}$, Opanasopit P, Kumpugdee-Vollrath M. Effect of terpenes on the skin permeation of ketoprofen through shed snake skin. Silpakorn Univ Sci Tech J, 2009; $3(2): 33$.

Cevc G, Blume G. Investigation of the mechanism of enhanced skin penetration by ultradeformable liposomes. Biochim Biophys Acta, 1992; 1104(1):226.

Cornwell PA, Barry BW. Sesquiterpene components of volatile oils as skin penetration enhancers for the hydrophilic permeant 5-fluorouracil. J Pharm Pharmacol, 1994; 46:261-9.

Dragicevic-Curic N, Friedrich M, Petersen S, Scheglmann D, Douroumis D, Plass W, Fahr A. Assessment of fluidity of different invasomes by electron spin resonance and differential scanning calorimetry. Int J Pharm, 2011; 412:85-94. 
Dragicevic-Curic N, Gräfe S, Albrecht V, Fahr A. Topical application of temoporfin loaded invasomes for photodynamic therapy of subcutaneously implanted tumour in mice: A pilot study. J Photochem Photobiol B Biol, 2008; 9:41-50.

Dragicevic-Curic N, Scheglmann D, Albrecht V, Fahr A. Temoporfin-loaded invasomes: development, characterization and in vitro skin penetration studies. J Control Release, 2008; 127(1):59.

Dwibhashyam VS, Ratna VJ. Chemical penetration enhancersan update. Indian Drugs, 2010; 47:5-18.

Fox LT, Gerber M, Plessis JD, Hamman JH. Transdermal drug delivery enhancement by compounds of natural origin. Molecules, 2011; 16:10507-40.

El-Nabarawi MA, Shamma RN, Farouk F, Nasralla SM. Dapsone-loaded invasomes as a potential treatment of acne: preparation, characterization, and in vivo skin deposition assay. AAPS Pharm SciTech, 2018; 19(5):2174-84; doi:10.1208/s12249-018-1025-0.

Haag SF, Fleige E, Chen M, Fahr A, Teutloff C, Bittl R, Lademann J, Schäfer-Korting M, Haag R, Meinke MC. Skin penetration enhancement of core-multishell nanotransporters and invasomes measured by electron paramagnetic resonance spectroscopy. Int J Pharm, 2011; 416:223.

Kalpana B, Lakshmi PK. Transdermal permeation enhancement of Tolterodine Tartrate through invasomes and iontophoresis. Der Pharmacia Lett, 2013; 5(6):119-26.

Kirjavainen M, Urti A, Jääskeläinen L, Suhonen TM, Paronen P, Valjakka-Koskela R, Kiesvaara J, Mönkkönen J. Interaction of liposomes with human skin in vitro - the influence of lipid composition and structure. Biochim Biophys Acta, 1996; 1304:179.

Lakshmi PK, Mounica V, Manoj KY, Prasanthi D. Preparation and evaluation of curcumin invasomes. Int J Drug Deliv, 2014; 6(2):113-20.

Latha K, Lalitha P, Basha SN. Formulation and evaluation of darifenacin hydrobromide nano-liposomes. J Chem Pharm Res, 2017; 9(4):173-82.

Liu KC, Green CR, Alany RG, Rupenthal ID. Synergistic effect of chemical penetration enhancer and iontophoresis on transappendageal transport of oligodeoxynucleotides. Int J Pharm, 2013; 441(1-2):687-92.

Maghraby GMME, Williams AC, Barry BW. Skin delivery of 5-fluorouracil from ultra deformable and standard liposomes in vitro. $\mathrm{J}$ Pharma Pharmacol, 2001; 53:1069-77.

Miller WR. Aromatase inhibitors: mechanism of action and role in the treatment of breast cancer. Semin Oncol, 2003; (4 Suppl 14):3-11.

Badran M, Shazly G, El-Badry M. Effect of terpene liposomes on the transdermal delivery of hydrophobic model drug, nimesulide: characterization, stability and in vitro skin permeation. Afr J Pharm Pharmacol, 2012; 6(43):3018-26.

Mura S, Manconi M, Sinico C, Valenti D, Fadda AM. Penetration enhancer-containing vesicles (PEVs) as carriers for cutaneous delivery of minoxidil. Int J Pharm, 2009; 380(1-2):72-9.

Paradkar A, Ambike AA, Jadhav BK, Mahadik KR. Characterization of curcumin PVP solid dispersion obtained by spray drying. Int J Pharm, 2004; 271:281-6.
Patel M, Joshi A, Hassanzadeth H, Juluru R, Stagni G. Quantification of dermal and transdermal delivery of meloxicam gels in rabbits. Drug Dev Ind Pharm, 2011;37(5):613-7.

Prajapati A, Shah D, Jani J, Singh S. Fabrication of sustained release matrix tablet of lornoxicam: influence of hydrophilic and hydrophobic polymers on the release rate and in vitro evaluation by 32 full factorial design. Invent Rapid NDDS, 2012; 4:1-14.

Prasanthi D, Lakshmi PK. Terpenes: Effect of lipophilicity in enhancing transdermal delivery of alfuzosin hydrochloride. J Adv Pharm Technol Res, 2012; 3(4):216-23.

Prasanthi D, Lakshmi PK. Iontophoretic transdermal delivery of finasteride in vesicular invasomal carriers. Pharm Nanotechnol, 2013; $1: 136-86$.

Ravi R, Sharad V, Attaullah K, Parul S. Formulation and evaluation of 5-fluorouracil loaded liposomes. Int J Phytopharmacol Res, 2012; 2(3):222-8

Sammeta SM, Repka MA, Narasimha Murthy S. Magnetophoresis in combination with chemical enhancers for transdermal drug delivery. Drug Dev Ind Pharm, 2011; 37(9):1076-82.

Singla V, Saini S, Singh G, Rana AC, Baibhav J. Penetration enhancers: a novel strategy for enhancing transdermal drug delivery. Int Res J Pharm, 2011; 2:32-6.

Upadhyay N, Mandal S, Bhatia L, Shailesh S, Chauhan P. A review on ethosomes: an emerging approach for drug delivery through the skin. Recent Res Sci Technol, 2011; 3(7):19.

Verma DD, Fahr A. Synergistic penetration enhancement effect of ethanol and phospholipids on the topical deliver of cyclosporine A. J Control Release, 2004; 97:55-66.

Verma DD, Verma S, Blume G, Fahr A. Particle size of liposomes influences dermal delivery of substance into skin. Int J Pharm, $2003 ; 258: 271-80$.

Verma DD, Verma S, McElwee K, Freyschmidt-Paul P, Hoffman R, Fahr A. Treatment of alopecia areata in the DEBR model using Cyclosporin a lipid vesicle. Eur J Dermatol, 2004; 14(5):332-8.

Williams AC, Barry BW. Penetration enhancers. Adv Drug Deliv Rev, 2004; 56:603-18.

Zellmer S, Pfeil W, Lasch J. Interaction of phosphatidylcholine liposomes with the human stratum corneum Biochim. Biophys Acta, 1995; 1237:176

How to cite this article:

Vidya K, Lakshmi PK. Cytotoxic effect of transdermal invasomal anastrozole gel on MCF-7 breast cancer cell line. $\mathrm{J}$ Appl Pharm Sci, 2019; 9(03):050-058. 